\title{
Understanding the Mechanisums that Regulate Coho Salmon Abundance in the Strait of Georgia, British Columbia, Canada
}

\author{
Chrys-Ellen M. Neville and Richard J. Beamish \\ Fisheries and Oceans Canada, Pacific Biological Station, 3190 Hammond Bay Road, Nanaimo, BC V9T 6N7 \\ Canada
}

Keywords: Coho salmon, migration, Strait of Georgia, metabolic threshold

There was an important commercial and recreational fishery for coho salmon in the Strait of Georgia, British Columbia, Canada in the 1970s and 1980s. The recreational fishery was one of the largest in Canada with average annual catches of 508,000 fish from 1980 to 1990 (Beamish et al. 1999). However, in the late 1980s, it was evident that abundances were declining (DFO 1990, 1992; Irvine et al. 1992). The declines continued into the 1990s with the closure of the commercial fishery in 1995 and the recreational catches diminishing to very low levels after 1994 (Beamish et al. 2008). The declines in abundance were related to the loss of freshwater habitat and to an exploitation rate that was too high (DFO 1990, 1992). However, the synchronous declines in abundance for coho salmon from the Strait of Georgia, Puget Sound and off the coasts of Washington and Oregon (Beamish et al. 2000) indicated that the major reason for the declines resulted from a declining marine survival that was related to a change in the ocean ecosystem. Importantly, the abundance declines in all these areas occurred despite additions of smolts from hatcheries that annually averaged about 100 million fish (Beamish et al. 1997), clearly showing that the declines were mainly a result of changing ocean conditions.

Coho salmon smolts enter the marine environment in about May and remain and rear within the Strait of Georgia until October or November (Chittenden et al. 2009; Beamish et al. 2010). Historically, coho salmon originating from rivers flowing into the Strait of Georgia were caught within the strait and off the southwest portion of Vancouver Island. Prior to 1994, the proportion captured within the strait or outside of the strait varied among years. When catches were greater outside the Strait of Georgia, the year was classified as an outside year and an inside year when the proportion was greater within the strait (Beamish et al.1999). From the mid-1970s through to the early 1990s, there was no trend in the inside or outside catches. Beginning in 1995, virtually all juvenile coho salmon left the Strait of Georgia late in their first ocean year and did not return until their spawning migration later in their second ocean year (Beamish et al. 1999). Thus, the collapse of the recreational fishery resulted from this behavioural change during their first marine winter as well as a decline in marine survival from about $10 \%$ in the late 1970s to about 1\% in the 1990s (Beamish et al. 2010). Our discussions with First Nations Elders on Vancouver Island indicate that historically the presence of coho salmon in the Strait of Georgia in all months was typical and that these fish were so numerous they could be readily caught throughout the year. Thus, the migration out of the Strait of Georgia beginning in 1995 represented a behavioural change that was unprecedented

In this study, we show that abundances of coho salmon occurred within the Strait of Georgia in the winter of 2017-2018 for the first time since 1994. These fish remained in the strait until they returned to their natal rivers. We speculate that the change in migratory behaviour was related to improved growth in the early marine period in the Strait of Georgia.

Methods

Surveys examining the distribution and abundance of juvenile salmon in the Strait of Georgia have been conducted in the early summer (June/July) and early fall (September) each year since 1998. The standard track line extending from Cape Mudge in the northern Strait of Georgia to the Canada/US border in the south is surveyed (Fig. 1). The surveys use a modified mid-water trawl with a mouth opening of approximately $14 \mathrm{~m}$ deep by $30 \mathrm{~m}$ wide and with small mesh cod-end designed to retain juvenile salmon. Fishing occurs at $15 \mathrm{~m}$ depth intervals from the surface to $60 \mathrm{~m}$ head-rope depth and sets are typically 30 minutes. Detailed information on the survey protocol is provided in Beamish et al. (2000) and Sweeting et al (2003). Random or haphazard samples of juvenile Pacific salmon (30100 per set) are selected and measured for fork-length (mm). Catch-per-unit-effort (CPUE) is calculated by set and by survey and is standardized to catch per hour.

Stock composition of the coho salmon collected in the Strait of Georgia has been determined using DNA analysis since 2008. DNA analysis is conducted using a small piece of fin tissue collected during sampling and stored in 95\% ethanol. The analysis is conducted at the Molecular Genetics Laboratory at the Pacific Biological Station in Nanaimo, BC following the procedures described in Beacham et al. (2012). 
In addition to samples collected from the annual trawl surveys, information was collected from a group of recreational anglers. This small group of recreational anglers joined together in 2014 to report on Pacific salmon fishing in the Strait of Georgia and to provide tissue samples for DNA analysis of coho and Chinook salmon. Their observations are the only information about the winter residence of Pacific salmon in the Strait of Georgia. Their sampling is opportunistic and their effort is not quantifiable, however, it is knowledge provided by experienced individuals.

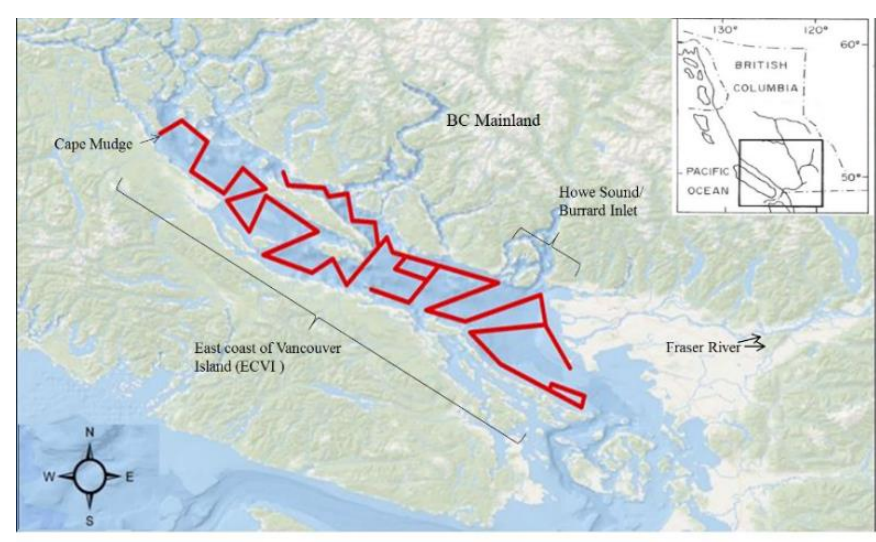

Fig. 1. Map showing location of the Strait of Georgia and location of standard survey track lines (red line) fished each year during the juvenile salmon surveys.

\section{Results and Discussion}

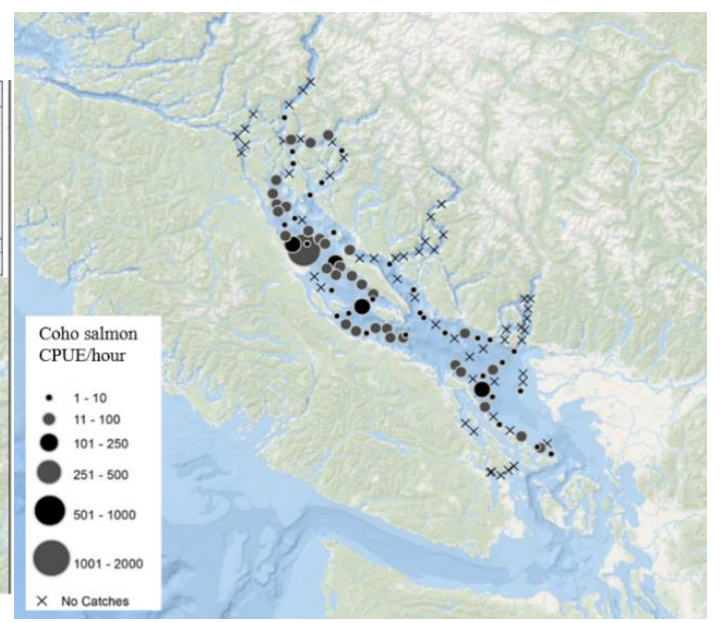

Fig. 2. CPUE by set of coho salmon in September 2014 as an example of general distribution patterns. X's indicate sets conducted with no coho salmon captured. This distribution pattern is typical of September with coho captured throughout the study area but with larger concentrations in the northern portion of the strait

The distribution of the catch of juvenile coho salmon in September did not change substantially over the 20year survey period with coho salmon captured throughout the study region but with the greatest numbers in the northern portion of the strait (Fig. 2). The catch of juvenile coho salmon in the September trawl surveys declined between 1998 and 2008 (Fig. 3). The lowest catch was recorded in the survey in 2008 with less than 5 juvenile coho salmon captured per hour (Fig. 3). Following 2008, the catch of coho salmon began to increase. From 2012 and 2017, four of the largest catch years in the 20-year survey period were recorded (Fig. 3). In 2016, the survey was conducted in late October due to issues with the research vessel, and results from this delayed survey are not included in this analysis.

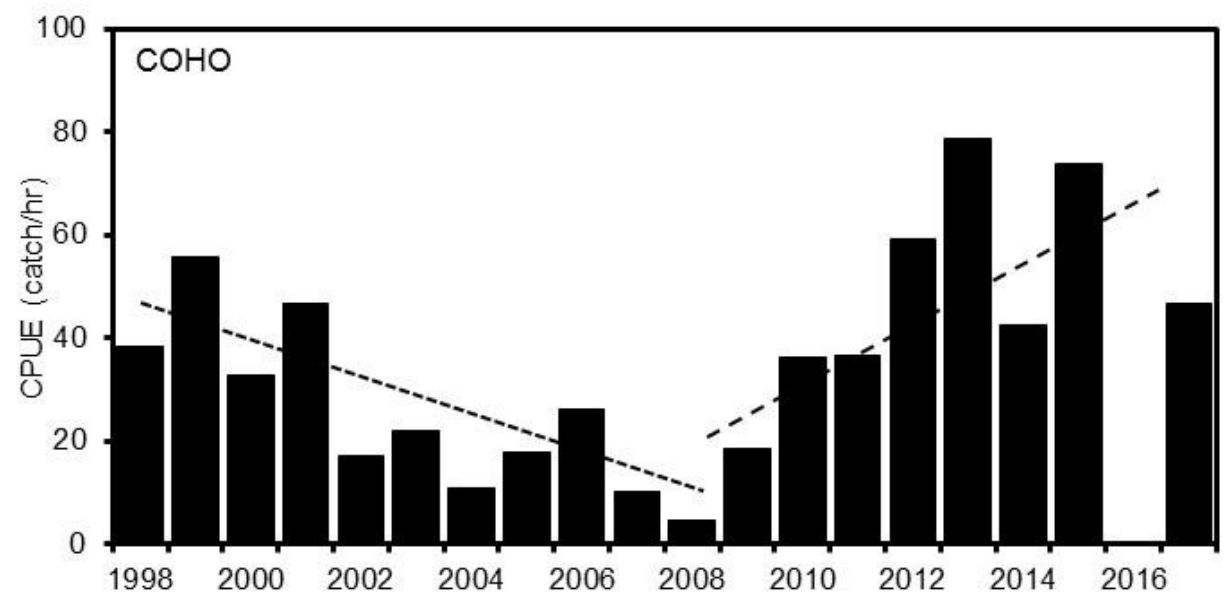

Fig. 3. CPUE (catch per hour) of coho salmon in the September trawl surveys 1998-2017 showing declining trend 1998 to $2008\left(R^{2}=0.661\right)$ and increasing trend since $2008\left(R^{2}=0.487\right) .2016$ is excluded due to delayed timing of survey. 


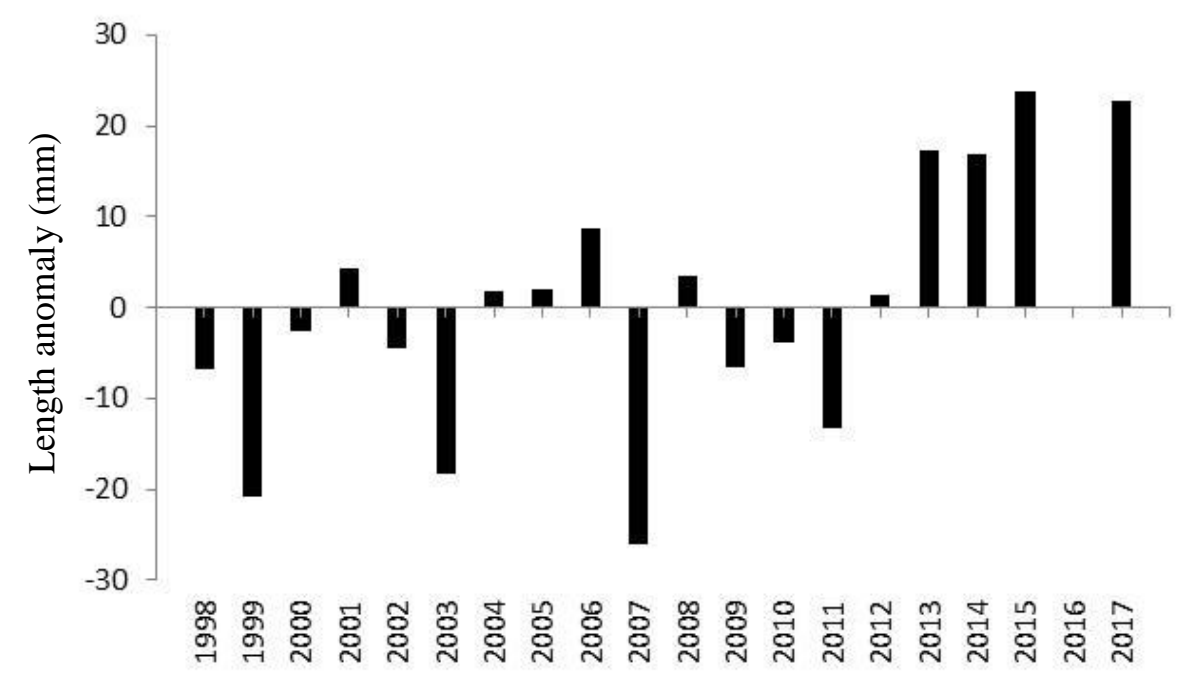

Fig. 4. The anomaly of fork length from the 20-year average for coho salmon during their first September at sea.

Concurrent with the increasing catch of coho salmon in September following 2008, there has been an increase in the length of the juveniles. Between 1998 and 2008 there was no trend in the average size of the juvenile coho salmon. Since 2013 the average size of the juveniles has been above the 20 -year average in every year (Fig. 4). An analysis of variance (ANOVA) showed significant differences in the lengths $(\mathrm{F}(18,19846)=269.9, p<0.001)$. A post hoc Tukey test showed that the average lengths of the juvenile coho salmon in 2013 to 2017 was significantly greater than each of the 16 years prior $(p<0.001)$.

Beginning in 2013, we received reports from the anglers that coho salmon were in the southern strait near the mouth of the Fraser River in the late winter. Estimates of abundances are only guesses, but based on their reports it appears that the numbers of coho salmon in the late winter have been increasing since 2013.

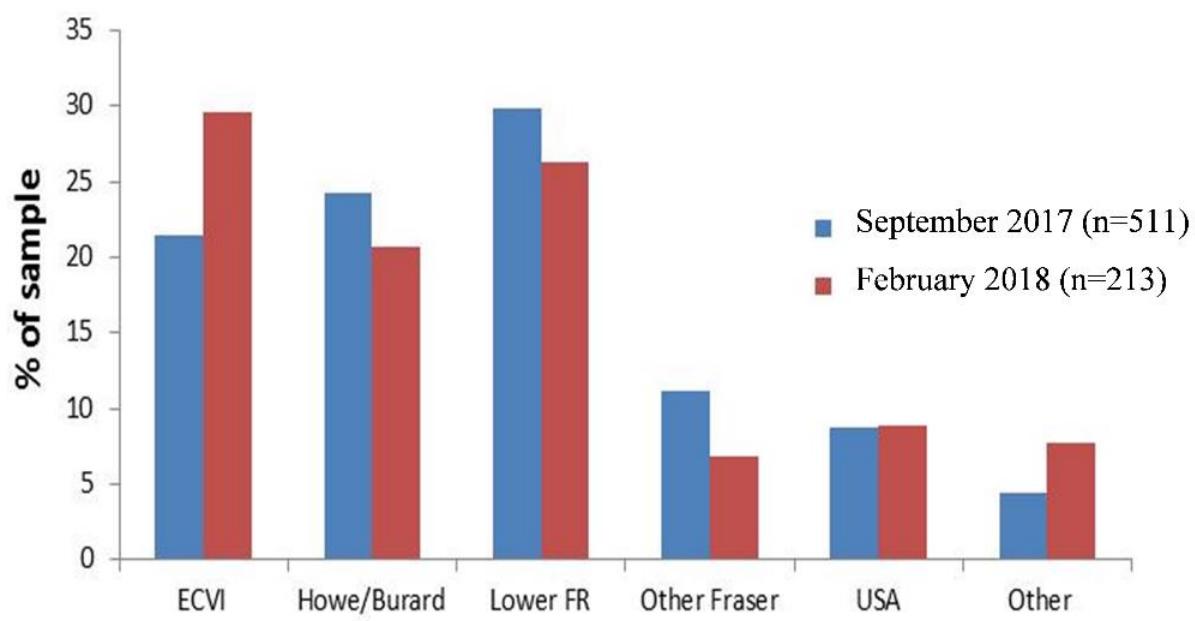

Fig. 5. The stock composition of coho salmon captured in September 2017 in the trawl survey and in February 2018 by the anglers. ECVI - east coast Vancouver Island; Howe/Burrard - Howe Sound and Burrard Inlet region on southern BC mainland coast; Lower FR - lower Fraser River; Other Fraser - all areas of Fraser River above lower Fraser River combined; USA - Puget Sound and Washington State; Other-BC mainland coast north of Howe/Burrard Inlet.

In September 2017, the catch and average size of juvenile coho salmon in the trawl surveys remained above average. The stock mixture was dominated by lower Fraser River, Howe/Burrard and east coast Vancouver Island (ECVI) coho salmon representing about $30 \%, 24 \%$, and $22 \%$ of the catch respectively. In addition, smaller numbers of coho salmon from other regions of the Fraser River (12\%) and Puget Sound (9\%) were captured (Fig. 5). 
In January 2018, anglers reported large abundances of coho salmon in the central Strait of Georgia. There were reports of coho salmon jumping and densities so large that the frustrated anglers frequently caught coho salmon as they tried to get their lines into deeper water to catch Chinook salmon. In February 2018, anglers collected tissue samples for DNA analysis from 213 coho salmon. The schools being fished were distributed throughout the western side of the central Strait of Georgia with some individual schools estimated to be several km wide and fish within these schools distributed from the surface to $60 \mathrm{~m}$. The stock composition of these fish collected by the anglers was virtually identical with the observations in the trawl survey five months earlier (Fig. 5).

Prior to 1995, wild and hatchery-reared coho salmon from rivers flowing into the Strait of Georgia were caught in their second ocean year in the strait and off the west coast of Vancouver Island. The percentage caught in the two areas varied among years with a weak relationship to the surface salinity in the Strait of Georgia in February (Beamish et al. 1999). Movement out of the strait occurred before February, so the salinity relationship was an indicator of an effect of earlier ocean conditions. The similar behaviour of hatchery and wild fish showed that the migration response likely was related to a metabolic process common to all coho salmon. The movement of virtually all ocean-age-1 coho salmon offshore beginning in 1995 also shows that there were not migratory and nonmigratory types as proposed by Healey (1978). Thus, we propose that there was a mechanism that regulated the migratory behaviour of the juvenile coho salmon that was related to metabolic processes and the mechanism would need to be queued by external events.

The increased trend in average lengths and CPUE beginning in September 2013 shows that it is likely that prey abundances were increasing, allowing more energy to be available for growth. We propose that in 2017, the growth increases were sufficient to allow some individuals to remain in the Strait of Georgia. For this to happen, it is possible that the increases in average length that started in 2013 resulted in growth in 2017 that enabled some fish to exceed a metabolic threshold at a critical time in their development. The importance of metabolic thresholds in the development of fishes is discussed by Beamish (2018) and is the basis of the critical size-critical period hypothesis by Beamish and Mahnken (2001). Importantly, it is the faster-growing individuals (that could also be larger) that become resident. The individuals that were smaller at the critical period would not exceed a metabolic threshold and would be programmed to migrate out of the Strait of Georgia in the fall, presumably in search of better feeding opportunities. According to this hypothesis, the inshore and offshore migratory behaviour prior to 1995 would also reflect the percentage of fishes that did or did not exceed the metabolic threshold at the critical period of development. The relationship with the February salinity in the Strait of Georgia could relate to reduced prey abundances when winds forced more Fraser River water to be retained in the Strait of Georgia. The movement of virtually all juveniles out of the strait beginning in 1995 could also result from an extreme reduction in prey abundances with virtually all fish not exceeding a metabolic threshold. It was in the early 1990s that production of Fraser River sockeye salmon also started to decline (Beamish et al. 2012), possibly indicating that a large-scale decline in prey abundance was occurring at the time smolts were entering the ocean.

One difficulty with our interpretation is that the length anomalies in Figure 4 do not show a gradual increase from 2013 to 2017. The critical size-critical period hypothesis includes a possibility that fish not exceeding a metabolic threshold will continue to use more energy for growth and store fewer lipids (Beamish et al. 2008; Beamish et al. 2018; Beamish 2018). According to this speculation, it would not be until 2017 that large numbers of fish exceeded the metabolic threshold and thus were not metabolically programmed to migrate offshore. Beamish et al. (2008) found that growth of juvenile coho salmon in the Strait of Georgia between July and September was inversely related to marine survival suggesting that coho salmon that were larger in July grew less and survived better because they were storing more lipids than the smaller fish. It is also possible that beginning in 2013 there were coho salmon resident within the Strait of Georgia throughout the winter, but the abundances were low and not noticed by the recreational anglers.

Our interpretation of the factors affecting the migratory behaviour of juvenile coho salmon can be tested by comparing the otolith daily growth zones of juveniles that are now resident with the fish from the same brood year that migrate offshore. This could not be done from 1995 to 2017 as coho salmon were not resident. Individuals that are now resident would have wider daily growth zones up to the critical period than those that migrate offshore late in their first ocean year. The daily growth zones in the otoliths of the resident fish may be narrower after the critical period as the fish begin to store lipids and use less energy for growth.

The concept that the behavioural change in 1995 and the outside-inside abundances prior to 1995 are a consequence of a metabolic regulated threshold that is cued at a critical time in development is similar to the process that must occur at the time coho salmon are ready to smolt. It is well known that juvenile coho salmon smolt at a number of freshwater ages and that the metabolic decision to smolt is considered to be related to energy storage (Sandercock, 
1991; Quinn 2005; Beamish et al. 2018). We are proposing that similar to the process that regulated smolting, there is a metabolic threshold that regulates the migration patterns of the coho salmon during their first marine winter.

\section{REFERENCES}

Beacham, T.D., J.R. Candy, C. Wallace, M. Wetklo, L. Deng, and C. MacConnachie. 2012. Microsatellite mixed stock identification of coho salmon in British Columbia. Marine and Coastal Fisheries 4 (1): 85-100.

Beamish, R.J., C. Mahnken, and C.M. Neville. 1997. Hatchery and wild production of Pacific salmon in relation to large-scale, natural shifts in the productivity of the marine environment. ICES J. Mar. Sci. 54: 1200-1215.

Beamish, R.J., G.A. McFarlane, and R.E. Thomson. 1999. Recent declines in the recreational catch of coho salmon (Oncorhynchus kisutch) in the Strait of Georgia are related to climate. Can. J. Fish. Aquat. Sci. 56: 506-515.

Beamish, R.J., D. McCaughran, J.R. King, R.M. Sweeting, and G.A. McFarlane. 2000. Estimating the abundance of juvenile coho salmon in the Strait of Georgia by means of surface trawls. N. Am. J. Fish. Manage. 20: $369-375$.

Beamish, R.J. and C. Mahnken. 2001. A critical size and period hypothesis to explain natural regulation of salmon abundance and the linkage to climate and climate change. Prog. Oceanogr. 49: 423-437.

Beamish, R.J., R.M. Sweeting, K.L. Lange, and C.M. Neville. 2008. Changes in the population ecology of hatchery and wild coho salmon in the Strait of Georgia. Trans. Am. Fish. Soc. 137:503-520.

Beamish, R.J., R.M. Sweeting, K.L. Lange, D.J. Noakes, D. Preikshot, and C.M. Neville. 2010. Early marine survival of coho salmon in the Strait of Georgia declines to very low levels. Marine and Coastal Fisheries: Dynamics, Management, and Ecosystem Science 2:424-439.

Beamish, R.J., C. Neville, R. Sweeting, and K. Lange. 2012. A synchronous failure of juvenile Pacific salmon and herring production in the Strait of Georgia in 2007 and the poor return of sockeye salmon to the Fraser River in 2009. Marine and Coastal Fisheries: Dynamics, Management, and Ecosystem Science 4(1):403-414.

Beamish, R.J., L.A. Weitkamp, L.D. Shaul, and V.I. Radchenko. 2018. Chapter 4: Ocean Ecology of Coho Salmon. Pages 391-533 in R.J. Beamish (Editor) The Ocean Ecology of Pacific Salmon and Trout. Am. Fish. Soc., Bethesda Maryland.

Beamish, R.J. 2018. Teaming up internationally to optimize wild and hatchery Pacific salmon production in a future of changing ocean ecosystems-the International Year of the Salmon (IYS). N. Pac. Anadr. Fish Comm. Tech. Rep. 11. (Available at http://www.npafc.org)

Chittenden, C.M., R.J. Beamish, C.M. Neville, R.M. Sweeting, and R.S. McKinley. 2009. The use of acoustic tags to determine the timing and location of the juvenile coho salmon migration out of the Strait of Georgia,

Canada. Trans. Am. Fish. Soc. 138:1220-1225.

DFO (Department of Fisheries and Oceans Canada). 1990. Strait of Georgia coho resource status and management planning process. September 1990. DFO, Nanaimo, British Columbia, Canada. Available: paclibrarypbs@pac.dfo-mpo.gc.ca.

DFO (Department of Fisheries and Oceans Canada). 1992. Strait of Georgia coho salmon planning process and recommendations: South Coast coho initiative final report, March 1992. Coho Steering Committee Final Report. Vancouver, Canada.

Healey, M.C. 1978. The distribution, abundance, and feeding habits of juvenile Pacific salmon in Georgia Strait, British Columbia. Fish Mar. Serv. Tech. Rep. No. 788.

Irvine, J.R., A.D. Andersons, V. Haist, B.M. Leaman, S.M. McKinnell, R.D. Stanley, and G. Thomas. 1992. Pacific stock assessment review committee annual report for 1991. Can. Man. Rep. Fish. Aquat. Sci. No. 2159.

Quinn, T.P. 2005. The behaviour and ecology of Pacific salmon and trout. Univ. Washington Press, Seattle. 378 pp.

Sandercock, F.K. 1991. Life history of Coho Salmon (Oncorhynchus kisutch). Pages 395-445 in C. Groot and L. Margolis, Editors. Pacific salmon life histories. Univ. British Columbia Press, Vancouver.

Sweeting, R.M., R.J. Beamish, D.J. Noakes, and C.M. Neville. 2003. Replacement of wild coho salmon by hatchery-reared coho salmon in the Strait of Georgia over the past three decades. N. Am. J. Fish. Manage. 23: $492-502$. 